\title{
Pisom q'aq'al: la majestad envuelta. Poder, reliquias y el "poder de las reliquias" entre los mayas prehispánicos
}

\author{
Pisom q'aq'al: the Bundled Majesty. Power, Relics, \\ and the "Power of Relics" among the Prehispanic Maya
}

\author{
Rocío Maza García de Alba \\ École Pratiques des Hautes Études, Francia
}

\begin{abstract}
REsumen: La preservación de restos humanos, muchas veces contenidos en envoltorios, fue una práctica común entre los mayas prehispánicos. Este artículo explica el interés por conservar tales reliquias en virtud del contenido anímico que resguardaban, que parece haber sido una cualidad solar, masculina, con poder seminal y de manifestación majestuosa. En un primer momento discuto, a través de la información presente en fuentes históricas, algunos de los tratamientos mortuorios que conducían a la generación de reliquias, así como los contextos en los que éstas eran conservadas y los usos sociales a los que estaban destinadas en tiempos cercanos a la llegada de los españoles. Distingo tres tipos principales de reliquias: las reliquias domésticas relacionadas con un linaje, las de los dioses o ancestros fundadores, de importancia comunitaria, y las de los sacrificados y cautivos, asociadas con la noción de trofeos de guerra. El análisis conjunto de estas categorías abre las vías para interrogar las concepciones mayas sobre los ancestros, la conformación de la persona y el ejercicio de la autoridad, que explican la importancia ritual de las reliquias y su papel en la legitimación del poder. A partir de estas cuestiones, indago en un segundo momento en la naturaleza del poder intrínseco que se adjudicaba a dichos objetos. Para ello parto de la denominación dada al envoltorio sagrado de los fundadores quichés: pisom q'aq'al, término que revela la consideración de las reliquias como custodias de cierto "fuego", q'aq', o "majestad”, q'aq'al, identificable con una fuerza o calor vital asociado con el poder, que ha sido documentado tanto etnográficamente como en fuentes históricas y linguísticas coloniales entre distintos grupos mayas con nombres variables, pero manteniendo rasgos característicos que dan cuenta de una concepción compartida, con antecedentes en las cualidades solares de los señores del período Clásico.
\end{abstract}

Palabras clave: mayas, reliquias, poder, envoltorios sagrados, k'inam, pisom q'aq'al.

ABSTRACT: Ancient Maya used to preserve relics, commonly wrapped in sacred bundles. Archaeological and historical sources allow us to know the mortuary treatments which led to obtain those relics, the different contexts in which they were placed and the social uses to which they were destined. I distinguish between three types of relics: domestic relics related to a lineage; those of gods or founding ancestors of a community, and those of the sacrificed and captives, associated with war trophies. Their joint analysis provides important information regarding Maya conceptions 
about ancestors, personhood and authority, which explain the ritual importance of relics, the meanings available in them and their role in legitimating power. The name of the sacred bundle left by Quiche founders, the pisom q'aq'al -bundled majesty-, leads.us to think that relics were preserved and venerated because they held a certain "fire", q'aq', or "majesty", q'aq'al, whose characteristics can be identified with a vital force or soul component, which increases by the exercise of authority that ethnographers and linguists have recorded under various names. Among them are derived forms of q'aq'al in Quiché, Cakchiquel and Tzotzil, and k'inam in Yucatec which seem to be closely related with the classical k'ihnich by its fiery, fierce and solar qualities

KeYwoRds: Maya, relics, authority, sacred bundles, k'inam, pisom q'aq'al.

Résumé: La préservation de reliques était une pratique courante chez les mayas précolombiens. Nous connaissons certains des traitements mortuaires qui favorisaient la génération des reliques ; les contextes rituels dans lesquels elles étaient inscrites et les usages sociaux auxquels on les destinait. Parmi les reliques, on peut distinguer: les reliques domestiques d'un lignage; celles des dieux ou des ancêtres fondateurs, d'importance communautaire -souvent des paquets sacrés- et celles des captifs et des sacrifiés, associées avec la notion de trophée de guerre. Leur analyse nous permet d'approcher les conceptions des anciens mayas concernant les ancêtres, l'autorité, et la notion de la personne, qui expliquent l'importance rituelle des reliques, ainsi que leur rôle dans la légitimation du pouvoir. Pisom q'aq'al (la majesté enveloppée), le nom du paquet sacré des fondateurs des lignages dominants quichés, nous permet d'avancer qu'elles étaient censées être des réceptacles d'un certain feu, q'aq', ou majesté, q'aq'al, que nous proposons d'identifier, d'après ses caractéristiques, avec une force vitale recensée par les ethnologues et les linguistes parmi des groupes mayas différents sous des noms également diverses, mais dont les caractéristiques, tels que son association aux charges de pouvoir, et sa capacité d'être cumulée au cours du temps, par exemple, rendent compte d'une conception largement partagé et dont la profondeur historique est manifeste dans les liens qui rapprochent le q'aq'al ou k'ak'al des quiché et des tzotziles et la force k'inam des yucatèques contemporains et de la période coloniale, avec le terme k'ihnich de la période Classique.

Mots-clés: mayas, reliques, pouvoir, paquets sacrés, k’inam, pisom q'aq'al.

ReCEPCIÓN: 14 de diciembre de 2017.

ACEPTACIÓN: 16 de abril de 2018.

DOI: 10.19130/iifl.ecm.2019.53.948. 


\section{Prácticas mortuorias y reliquias}

-Hijo mío, tráeme los huesos de tu padre, aquellos que enterraste hace tres años; tengo muchos deseos de mirarlos.

Chilam Balam de Chumayel (Barrera Vázquez, 1972: 140)

En su estudio clásico sobre la representación colectiva de la muerte, Robert Hertz $(1970)^{1}$ planteó los fundamentos teóricos de las implicaciones de los segundos funerales y de la producción de reliquias ${ }^{2}$ en el contexto del culto a los ancestros. De acuerdo con este autor, la muerte implica un proceso de transición de duración variable en el cual ocurren tanto la disgregación de los componentes físicos y anímicos de la persona, como la transformación de su papel social, llevándole de la exclusión inicial de la sociedad de los vivos a la final integración en la sociedad de los ancestros. ${ }^{3}$ Así, en la fase posterior inmediata a la muerte, las representaciones referentes al cadáver en descomposición están aparejadas con el estado de peligrosa inquietud que se adjudica al alma ${ }^{4} \mathrm{y}$, en el ámbito social, con el duelo impuesto a los vivos durante el mismo periodo. Cuando el cuerpo alcanza el estado definitivo de esqueleto, se considera que el alma llega a su sitio de reposo final en el Más Allá, con lo cual deja de ser amenazante y adquiere el carácter protector de los ancestros, a cuya sociedad se incorpora. Esto permite a los sobrevivientes terminar con el duelo y llevar a cabo una segunda ceremonia funeraria para dar a los restos una sepultura permanente, inaugurando una etapa con "efectos favorables para los muertos, tanto como para los vivos" (Hertz, 1970: 44). Las reliquias resultantes comienzan a ser contempladas con respetuosa confianza, en calidad de mediadores materiales con el ancestro, ${ }^{5}$ que funge, a su vez, y a partir de entonces, como un mediador espiritual "entre los vivos y las fuerzas cósmicas" (Gillespie, 2002: 69).

${ }^{1}$ Su contribución a la sociología de la muerte parte del estudio de los dayaks de Borneo.

${ }^{2}$ El término reliquia procede del latin reliquiae (n. f. pl.), que significa "restos" y deriva, a su vez, del verbo relinquere, "dejar tras de sí, abandonar". Lo empleo aquí en su sentido etimológico y amplio de "restos".

${ }^{3}$ El enfoque de Hertz sobre los ritos mortuorios y las fases que distingue en las ceremonias de segundos funerales pueden ser articulados con el modelo de los ritos de paso propuesto por Arnold Van Gennep (1981). Markus Eberl (2005) lo ha aplicado al estudio de los mayas.

${ }^{4}$ En este contexto, el término alma no tiene las connotaciones derivadas del cristianismo, sino que hace referencia, de forma general, al o los componentes inmateriales que conforman el ser. La discusión sobre dichas concepciones entre los mayas prehispánicos rebasa los propósitos de este artículo. Véase al respecto la bibliografía de la nota 9 .

${ }^{5}$ De acuerdo con Susan Gillespie "los ancestros son el lazo metafísico que vincula a los miembros de una casa con sus orígenes. Continúan interviniendo en las experiencias cotidianas de los vivos y protegiendo a sus descendientes del mal, pero también castigándolos en caso de transgresión de los usos sociales y rituales, especialmente de los codificados como 'costumbres"' (Gillespie, 2000a: 144,145). Véase también Le Guen (2008). 
En el ámbito mesoamericano, podemos apreciar con suma claridad la manera en que el proceso de los segundos funerales conduce a la conformación de un envoltorio sagrado conteniendo reliquias gracias a los relatos de Jacinto de la Serna y de Cristóbal del Castillo sobre los restos de Huitzilopochtli. Las reproducimos a continuación, dado el interés que tienen por su relación con las prácticas mayas. De acuerdo con el primero de estos autores, después de muchos años de tenerlo a su servicio, el dios Tetzautéotl, agradecido, dijo al anciano Huitziton:

Tiempo es ya de que descanses pues eres ya viejo, y de que vengas a vivir eternamente entre nosotros; vuélvete pues, consuela tus hijos, avísales como ya son llegados tus días y que morirás presto, no les harás falta, pues tu calavera llevarán consigo y les guiará en lo que les falta de viaje. (De la Serna, 2014: 200)

Del Castillo complementa en su obra el contenido de este discurso, exponiendo cómo había de ser recuperada la calavera, tras la descomposición del cuerpo:

Aunque morirás, de modo que tu ánima estará con nosotros, a nuestro lado, no te desamparará nuestro teáchcauh Tetzauhtéotl, porque se asentará en tus huesos, en tu cráneo, y hablará a través de ti, como si tú allí estuvieses vivo [...] ordénales de esa manera que cuando salga tu ánima, cuando hayas muerto, entierren tu cuerpo en una caja de piedra, para que en ella estén tus huesos por cuatro años [hasta que] tu carne se pudra mucho más [hasta que] regrese a la tierra. Pero desde ahí llamarás a tus servidores, los tlenamacaque, y cuando te saquen, entonces pondrán tus huesos en el envoltorio, en el bulto, y los depositarán sobre el altar, sobre el templo, en un lugar bueno y recto estará el bulto, el envoltorio hecho con tus huesos (Del Castillo, 2001: 12).

Así pues, el envoltorio sagrado es, en este caso, ${ }^{6}$ un bulto mortuorio secundario $^{7}$ que fungía como un vínculo de comunicación con el dios.

Los mayas parecen haber considerado, al igual que otros pueblos mesoamericanos, ${ }^{8}$ que los restos corporales, lejos de ser meros residuos inertes, preservaban en sí parte de los componentes que en vida les animaron, ${ }^{9}$ o que tenían la capacidad de acogerlos de nuevo temporalmente, bajo determinadas circunstancias rituales. Es por ello que a través de los tratamientos que daban a las reliquias, perseguían repercusiones trascendentes en el mundo invisible, de

\footnotetext{
${ }^{6}$ Sobre los contenidos de otros envoltorios mayas, véanse Ayala, 2002 y Wagner, 2006. En cuanto a envoltorios mayas en el siglo xx: Christenson, 2001 y Mendelson, 1958. Para una visión general más amplia del tema de los envoltorios sagrados en Mesoamérica, véase especialmente Guernsey y Reilly, 2006.

${ }^{7}$ Es decir, producto de segundos funerales. Cabe recordar que recuperar y preservar los huesos de esta forma es práctica actual de los mayas de algunas partes de la península de Yucatán. Véanse, por ejemplo, Astor-Aguilera, 2010: 160; Tiesler, 2007.

${ }^{8}$ Sobre problemáticas relacionadas con la muerte en otros grupos mesoamericanos, veáse Fitzsimmons y Shimada, 2011.

${ }^{9}$ Véanse al respecto: Houston, Stuart y Taube, 2006; Velásquez, 2009; Bourdin, 2007.
} 
donde se desprende la gran importancia política que en este mundo les conferían. ${ }^{10}$ Su enorme valor simbólico es manifiesto en un amplio abanico de prácticas sociales, en cuyos extremos se oponían la veneración reverente y la profanación que aniquila.

Los contextos de consecución y preservación de reliquias nos permiten distinguir entre ellas tres tipos principales (Maza, 2014): las reliquias de linaje veneradas en oratorios domésticos, las de los ancestros fundadores y las personas de importancia comunitaria, muchas veces tenidas en envoltorios y depositadas en sitios sobresalientes dentro de la geografía sagrada maya, y las de los sacrificados y cautivos, asociadas con la noción de trofeos de guerra, cuyos tratamientos póstumos, sumamente variados, se orientaban de forma general al control de la fuerza de la persona capturada en beneficio del captor. Debido a la amplitud del tema y a la brevedad que precisa esta exposición, es inevitable que queden lagunas espaciales y temporales, algunas de suyo imposibles de colmar por el carácter fragmentario y la desigual prolijidad de las fuentes.

En este artículo sugiero que la conservación de reliquias deriva de su consideración como soportes de la fuerza anímica de la persona a quien pertenecían los restos. Para llegar a ello muestro los vínculos entre las características de la fuerza vital, k'inam (Villa Rojas, 1982, 1985; Chávez, 2005; Álvarez, 1997), y de otras concepciones semejantes (Vogt, 1979; Guiteras, 1965), con las que definen el pisom q'aq'al, la majestad envuelta, la reliquia de los principales linajes quichés. Existen, por una parte, importantes vínculos linguísticos (Villa Rojas, 1985, Laughlin, 1975; Wichmann, 2004), a los cuales dedicaré parte de la discusión. Lo principal, sin embargo, es que hay indicios para suponer que las concepciones a las que el léxico remite eran compartidas en gran parte del área maya y que su profundidad histórica es muy grande. Las recientes aportaciones de la epigrafía y la iconografía (Houston, Stuart y Taube, 2006; O’Neil, 2012) hablan de las cualidades solares de los antiguos señores mayas, asignándoles una naturaleza bravía, caliente, que los distinguía del resto de los mortales. A través de la información provista por las fuentes históricas y literarias mayas e hispanas del período cercano a la llegada de los españoles, parece evidente que los grandes señores del Posclásico eran caracterizados de manera semejante. El interés por preservar sus reliquias derivaría entonces del de mantener dentro del grupo esa fuerza grandiosa y protectora, que era ante todo una fuerza generadora de vida.

En la primera parte, "Reliquias y poder", me centraré en señalar algunas de las prácticas de conformación y preservación de reliquias que las fuentes históricas permiten conocer. Asimismo, buscaré dar seguimiento en el tiempo a la asociación de los poderosos con figuras clave de la religión maya a partir de los

10 Sobre los ritos funerarios de los reyes mayas y el papel de sus reliquias en el Clásico, véase: Fitzsimmons, 2009; acerca de la permanencia de los ancestros en la memoria social a partir de la integración de sus restos en la arquitectura, McAnany, 1998, y sobre el sacrificio humano y los tratamientos a los que eran sometidos los cuerpos de los sacrificados, Tiesler y Cucina, 2007. 
sitios que reservaban para su entierro y el depósito de sus restos. En el siguiente apartado, "El poder de las reliquias", analizaré las connotaciones del segundo componente del nombre dado en las fuentes quichés al envoltorio sagrado pisom q'aq'al, símbolo del poder del linaje Cavec, dejado por sus fundadores como reliquia o "señal de su ser". Al examinar las reliquias a la luz de la equivalencia de significado entre el apelativo clásico k’inich, la fuerza, k’inam, y el término q'aq'al, en su empleo como calificativos de los señores poderosos o del poder de los señores planteo explicar el fuego divino de los dirigentes mayas, que López Austin (1973: 122, 134, 149) considera propio de los hombres-dioses, poniéndolo en relación con una fuerza anímica acumulativa, asociada con el desempeño de funciones públicas que la etnografía ha documentado con relativa amplitud.

\section{Reliquias y poder}

Sabemos por las crónicas que, en el siglo xvı, los mayas conservaban reliquias en los templos. Así, por ejemplo, la expedición de Juan Díaz reportó la existencia en Cozumel de "una torrecilla de la altura de dos hombres uno sobre otro, y dentro tenía ciertas figuras, y huesos, y cenís, que son los ídolos que ellos adoraban”. (Benavente "Motolinía”, 1969: 260). ${ }^{11}$ Esta noticia plantea, en primer lugar, la cuestión de la procedencia de tales restos, que será preciso explorar.

Excavaciones en sitios como Caracol (Chase y Chase, 2011), K'axob (McAnany, 1998) y Tulum (Vargas y Santillán, 1992), han puesto de manifiesto el carácter habitual de las intervenciones secundarias en las tumbas desde el Preclásico Medio hasta la conquista en actividades relacionadas con la sucesión, legitimación y veneración a los ancestros.

Gracias a la correlación entre los datos arqueológicos e históricos, el sitio de Mayapán ofrece las evidencias más claras de un culto doméstico a los ancestros que, en el Posclásico Tardío, involucraba reliquias (Smith, 1962; Serafín y Peraza, 2007: 238, 239). Además de los templos comunitarios, había oratorios privados que albergaban bajo su suelo los huesos de los difuntos y que disponían de un altar contra el muro del fondo, donde tenía lugar el culto familiar. ${ }^{12}$ En el altar de una de estas estructuras, los remanentes de pies modelados en estuco indican que hubo dos personajes sentados, tal vez esculturas de ancestros familiares a

\footnotetext{
${ }^{11}$ La descripción de un templo en el Petén Itzá, nos ayuda a imaginar el interior de estos recintos. En su centro pendía: "de tres cintas de algodón de distintos colores una canilla de hueso, medio podrida sobre la cual había una corona, y más abajo una taleguilla, de tres cuartas de largo, conteniendo pedacitos de hueso. Debajo de esto había tres sahumadores (...) y algunas hojas de maíz envolviendo estoraque" (Villagutierre, 1985: 494).

12 Recientemente, las investigaciones de Masson y Peraza han confirmado la existencia de oratorios asociados con casas y plazas, así como la utilización de objetos rituales al exterior del muro que rodeaba el sector de élite de Mayapán. Ello demuestra que los cultos familiares, no eran exclusivos de la élite gobernante que vivía dentro de los límites del centro cívico de Mayapán, como había concluido originalmente el reporte de la Institución Carnegie (véase Masson y Peraza, 2004).
} 
quienes pudo estar consagrado el oratorio (Smith, 1962: 220, 221), lo cual concordiaría con la descripción de fray Diego de Landa sobre las prácticas de los señores Cocom, originarios de Mayapán, quienes "echaban las cenizas en estatuas huecas, hechas de barro, cuando (los muertos) eran muy señores” (Landa, 1983: 59). Junto a éstas y dentro de los mismos oratorios conservaban unas medias calaveras sobre las cuales estaban modeladas los rostros de sus antepasados. Interesantemente, el fraile nos informa sobre el tratamiento de cocción al que fueron sometidas las cabezas, acelerando así el proceso de obtención de los cráneos:

A los antiguos señores Cocom, habían cortado las cabezas cuando murieron, y cocidas, las limpiaron de la carne y después aserraron la mitad de la coronilla para atrás, dejando lo de adelante con las quijadas y dientes. A estas medias calaveras suplieron lo que de carne les faltaba con cierto betún y les dieron la perfección muy al propio de cuyas eran, y las tenían con las estatuas de las cenizas, ${ }^{13}$ todo lo cual tenían en los oratorios de las casas, con sus ídolos, en gran reverencia y acatamiento, y todos los días de sus fiestas y regocijos les hacían ofrendas de sus comidas para que nada les faltase en la otra vida, donde pensaban (que) sus almas descansaban y les aprovechaban sus dones (Landa, 1983: 59, 60).

Esto parece mostrar que tales reliquias eran concebidas como medios para dar continuidad a la existencia personal de los difuntos. También en las Tierras Altas se conservaban efigies semejantes durante el Posclásico. De acuerdo con fray Tomás de Coto se llamaba vinak qu a "la estatua que antiguamente hacían, en muriendo algún señor de las mismas cenizas de su cadáver. Y esto hacían para memoria suya" (Coto, 1983: 218). En otra parte dice que estos "idolillos" estaban compuestos con las cenizas de "los compañones de los caciques y esforzados capitanes” (Coto, 1983: 289). Fray Bartolomé de Las Casas habla con cierta extensión sobre ellas:

En algunas partes daban sepulturas a los difuntos que fueron señalados reyes, desta manera: esta era que los quemaban, y de las cenizas y reliquias que restaban formaban un cuerpo con gran artificio hecho. Esto era que con un hilo de oro tan grueso como se suele hacer de hierro, hacían la ligazón de todos los miembros; formaban y ligaban los dedos de los pies con el mismo hilo, y en cada dedo ponían una esmeralda u otra preciosa piedra [...] y (así) en todas las coyunturas [...] y en todos los encuentros de los miembros de todo el cuerpo, y en el pico de la nariz ponían maravillosamente ligadas las dichas piedras, cosa rica y artificio digno de ver. Estos corpecitos así hechos ponían en sus cajas de piedra o madera, y si eran de personas de quien la república hobiese algún beneficio de libertad o de señalado gobierno

${ }^{13}$ En el Cenote Sagrado de Chichén Itzá fueron recuperadas algunas estatuillas, una de las cuales tiene un hueco en la parte posterior, así como un cráneo con rostro modelado (Tozzer, 1941), identificables con las reliquias guardadas en los oratorios. Las posibilidades que este hallazgo sugiere ameritan investigación ulterior, ¿se trataría de ancestros capturados a los enemigos? ¿su depósito en el cenote habrá tenido el valor de un sacrificio?, ¿o fueron acaso ancestros propios enviados con los dioses para interceder por sus descendientes en momentos de suma necesidad? 
y gran utilidad común recebido, teníanlo en gran veneración y hacíanles sacrificios cuándo y cómo los ofrecían a los ídolos. (Las Casas, 1967, II: 527) ${ }^{14}$

En ambas noticias destaca que el interés por preservar parte del cuerpo iba aunado al de conservar una imagen del difunto. La mención de la convivencia de los ancestros con los ídolos de dioses en los altares y de los sacrificios ofrecidos conjuntamente a todos ellos apunta a que el proceso de ancestralización de los muertos daba lugar al de la divinización de los ancestros, al menos en algunos casos de líderes particularmente estimados o de fundadores de linaje. Cabe preguntarse la medida en que este proceso sucedía únicamente entre las personas de alto rango o si era algo generalizado, como lo sugeriría la difusión de los cultos domésticos entre toda la población (Lorenzen, 2005; Masson y Peraza, 2004; McAnany: 1998), si había diferencias cualitativas en la forma de concebir los espíritus de los campesinos y de los de los miembros de la élite (Houston, Stuart y Taube, 2006: 156) y, por último, qué clase relaciones sociales se establecían en ambos casos con los espíritus ancestrales.

La intención de conservar o de recrear los cuerpos para poder dar a los ancestros un sitio de asiento, tiene implicaciones profundas en el pensamiento maya. Susan Gillespie (2000a) ha discutido cómo los comportamientos pasivos, como estar sentado en la casa, poseen una connotación de estabilidad dentro de las imágenes del universo que los mayas construyen artificialmente en distintos ámbitos, como la milpa o el altar, tomando la casa como una estructura simbólica ejemplar (Gillespie, 2000a: 138, 139). Según este principio, a partir de la acción ritual, es posible inmovilizar a los espíritus dentro de objetos que, en forma concentrada, representan la casa en su conjunto y que funcionan a nivel doméstico y comunitario como puntos de contacto con el mundo de los espíritus; lugares donde los ancestros se sientan a esperar ofrendas, y de los que se convierten en protectores. En parecido orden de ideas, Karl Taube (1998) ha descrito el proceso de focalización de escala y de atención, por medio del cual se daba a un objeto, generalmente un incensario alusivo al fogón central y a los ancestros, el lugar de axis mundi dentro de un templo, constituyéndolo en un punto específico para comunicar con lo sagrado.

Así, el establecimiento ritual de centros del mundo parece haber dado a los huesos de los gobernantes y de los ancestros destacados el lugar de punto focal en distintas escalas, como lo indican los nombres de "corazón de la casa", "corazón del pueblo", "corazón del cielo, corazón de la tierra” (Ximénez, 1857: 131), que recibían los envoltorios sagrados.

Es interesante poner estos análisis en relación con los sitios de entierro y con los altares donde reposaban los restos humanos, ya que parecen haber sido luga-

\footnotetext{
${ }^{14}$ Actualmente subsiste en esta región una expresión donde los restos materiales del cuerpo remiten a los ancestros. Mientras que nantat designa a los ancestros en general, en el lenguaje ritual se les llama muchulic bak, "polvo de hueso" (Tedlock, 1992: 41, 42).
} 
res de residencia de los espíritus ancestrales y de interrelación entre ellos y los vivos. ${ }^{15}$ Fray Bartolomé de las Casas refiere que "encima de la sepultura hacían un altarito de obra de un codo de alto cal y piedra, muy bien blanqueado en el cual quemaban muy ordinariamente incienso y ofrecían otros sacrificios" (Las Casas, 1967, II: 527).

Contamos también con el testimonio de dos frailes dominicos, quienes en sus esfuerzos por reducir la región de Sacapulas se quejaban de la reticencia de los indígenas a abandonar los terrenos que habían heredado:

porque allí o tienen los huesos de sus abuelos o lo que es peor, tienen en los cementerios de sus casillas sus penates que llaman corazones de las casas, y así esta sola causa que para ellos no quererse mudar ni dejar sus antiguos solares era muy importante. ${ }^{16}$

Tal información nos permite vislumbrar los nexos entre el territorio y los restos de los ancestros, destacando su papel en la animación de determinados puntos geográficos y arquitectónicos, así como en la creación de centros rituales. Al respecto, Tomás López Medel consigna que para los quichés de Utatlán la mayor gloria que podían esperar los magistrados era que

en vida los amaban y honraban, y muertos los enterraban en las casas de sus cabildos y ayuntamientos, en aquel mismo lugar a donde se solían sentar para administrar justicia y para votar y ejecutar aquellas notables obras que en la república hicieron. (López Medel, 1990: 245)

La idea de fijar permanentemente la presencia de los muertos destacados en el lugar que en vida tuvieron en sitios públicos da cuenta de la veneración comunitaria de que eran objeto y de la inscripción de su persona como un referente en la vida y en la memoria social al darles asiento en un monumento (McAnany, 1998). Por ejemplo, entre los templos principales de Izamal uno estaba dedicado al dios solar K'inich K'ak' Mo', uno al gran capitán Jun Pik Tok', otro correspondía al antiguo gobernante Itzam Nah Thul, y otro más a Kabul, que era una reliquia de su mano o acaso una representación de ella. Así, la contiguiidad de las reliquias y estatuillas de los señores principales con las de los dioses en los oratorios replicaba su significación en escala arquitectónica, dentro del centro ceremonial. La arqueología ha corroborado la importancia histórica de este proceso, ya que los restos de personajes relevantes están muchas veces en el origen de las zonas ceremoniales (Spotts, 2013; McAnany, 1998).

15 Sobre los oratorios y pequeños templos destinados a albergar ancestros divinizados, véase Lorenzen, 2005.

16 "Carta de fray Juan de Torre y fray Juan de Cárdena al Emperador, 6 de diciembre de 1555", Archivo General de Indias, Audiencia de Guatemala, legajo 168, citada en Zamora, 1985: 156. 
Las ciudades mayas prehispánicas fueron reflejo de un orden social en el que los gobernantes tomaron el sitio central, presentándose en ocasiones como el árbol de la ceiba que sostiene el cielo (Baudez, 2002: 160; Sharer, 1999: 501), en alusión al origen de su linaje ancestral y divino y a su importancia en el funcionamiento del cosmos. Esto es especialmente patente en el período Clásico; sin embargo, existe continuidad hasta la época colonial, pues sabemos que en el Petén Itzá, a fines del siglo xviı, una representación de Yax Cheel Cab, "a la cual adoran junto a la columna de piedra el reyezuelo y los demás de su familia y parcialidad", se encontraba ante la casa del gobernante Canek (Avendaño y Loyola, 1997: 35), y que en las Tierras Altas una ceiba ocupaba el centro de algunas poblaciones mayas. Según refirió Núñez de la Vega (1988: 275), “debajo de ella hacen sus elecciones de alcaldes, y las sahuman con braseros y tienen por muy asentado que en las raíces de aquella ceiba es por donde viene su linaje”. Otros símbolos vinculaban a los poderosos directamente con las figuras centrales de la cosmovisión, especialmente con el dios solar (Miller y Taube, 1993: 106), con los señores de la tierra (Gillespie, 2001: 98) y con el dios del maíz (Vega, 2017: 60; Taube, 1998, 462). La colocación de sus restos mortales en sitios específicos, como montañas, cuevas y pirámides, que compartían significados relevantes en la trama mítica de los orígenes y en la explicación sobre el funcionamiento del cosmos, participó de tales asociaciones y contribuyó a consolidarlas.

La naturaleza de los entierros de la élite en las cuevas tiene sus raíces en el Preclásico Medio. En el centro de peregrinación de Naj Tunich, hay indicios de que buena parte de la actividad de culto se dirigía a las tumbas que fueron colocándose en su interior (Helmke y Brady, 2014). El aspecto político del ritual que se había desarrollado en este sitio lo convirtió en blanco para la profanación de las sepulturas y la propagación de incendios por parte de casas dinásticas rivales. Una enorme proporción de los acontecimientos registrados en las inscripciones se refiere a acciones ofensivas en cavernas con incendios, exhumaciones violentas y otras formas de destrucción emprendidas con el objetivo explícito de socavar la sacralidad de tales lugares. Los hechos bélicos en las cuevas parecen haber sido asimilados y encuadrados en un relato de confrontación mitológica entre el dios del maíz y los señores de la tierra, dentro del cual los personajes de la élite tomaban parte en el ciclo de vida, muerte y renacimiento del dios del maíz.

En relación con esto, Frans Blom (1954) notó la correspondencia entre dos tipos de modificación cefálica con sendos tipos de ofrendas en varias grutas del valle de San Cristóbal de Las Casas, en donde identificó prácticas de cremación, sepulturas secundarias y conformación de osarios. Los cráneos con modelado tabular erecto están acompañados con alfarería ordinaria, en tanto que las piezas cerámicas que acompañan los de tipo tabular oblicuo son de la mejor calidad producida en el esplendor del Clásico maya. Esto reviste un interés particular a la luz de los análisis de Pamela Geller (2011) sobre la modificación del cráneo como signo visible del estatus, pues según esta autora, el modelado oblicuo habría permitido a los nobles encarnar lo divino, reproduciendo el ideal estético de la 
cabeza cónica del dios del maíz. ${ }^{17}$ Las implicaciones cosmológicas de tal identificación conllevaban un programa político en el que los entierros de los dirigentes, las ceremonias conmemorativas de su muerte y la disposición de sus cuerpos y de sus reliquias en lugares significativos, concebidos como entradas al inframundo y sitios de origen de la vida y de regeneración biológica (Stone, 1995: 39-44), ${ }^{18}$ coadyuvaron a inscribirlos en el complejo de la fertilidad, asignándose a sus huesos el poder germinal de las semillas, ${ }^{19}$ como reservas del principio genitor masculino dentro de la cueva, espacio cerrado, secreto y húmedo, asimilado al útero y al ámbito femenino (Tuan, 1974: 28). En el Popol Vuh, la idea de generación de nueva vida y de resurrección a partir de los huesos está presente en el episodio donde la calavera de Hun Hunahpú dejó encinta a Ixquic (Ximénez, 1857: 3839) y en aquel otro donde los gemelos resurgieron vivos de las aguas, tras ser arrojados sus huesos al río, y molidos en piedra como harina de maíz (Ximénez, 1857: 70-71).

Es importante introducir aquí los envoltorios sagrados que en las fuentes se asocian con reliquias divinas. Si bien estos envoltorios suelen vincularse con los dioses fundadores y con los símbolos de poder dejados por ellos en las migraciones posclásicas, también hay envoltorios (ikatz) abundantemente representados en la iconografía del período Clásico, anudados o deshechos y mostrando contenidos muy diversos, a veces insignias reales, parafernalia ritual, instrumentos de autosacrificio, imágenes de dioses y huesos (Wagner, 2006: 65). Esto muestra que la acción de envolver y de descubrir determinados objetos en contexto ritual tenía antecedentes directos y gran antigüedad en la región maya. El vínculo de continuidad entre algunos de ellos con los envoltorios posclásicos parece ser la imbricación de la fertilidad con el linaje y los ancestros.

Entre los contenidos recurrentes de los envoltorios clásicos se encuentran estatuillas del dios que los epigrafistas han llamado "Jester God", figura mayor para los reyes mayas, que evocaba los conceptos del fogón de tres piedras y del centro del mundo, asociado también a la fertilidad y a la continuidad de los linajes (Taube, 1998). Si bien este dios no subsistió en el Posclásico, los yucatecos del periodo de contacto adoraban a Bolon Dz'acab, que parece tener significados próximos. Se trata de un dios de los tiempos primordiales que protegió el principio de la regeneración del universo, simbolizado por el envoltorio que hizo mezclando su semen con semillas diversas, y cuyo nombre podría significar "Linaje supremo" (Sotelo, 2002: 86). El Chilam Balam de Chumayel narra:

${ }^{17}$ Véase también Tiesler, 2012.

${ }^{18}$ Recuérdense asimismo las prácticas relacionadas con la cacería, donde los huesos de los animales son llevados a la cueva para que el señor de los animales dé vida a nuevos seres (Brown, 2005 y 2009).

${ }^{19}$ Ruz Sosa ha señalado la correspondencia semántica y conceptual entre las semillas y los huesos (Ruz, 1985: 200); véase también Houston, Stuart y Taube, 2006: 221. 
Y fueron cogidos los Trece dioses (...). Y cogieron habas molidas junto con su semen y, junto con su corazón, semilla molida de calabaza, y semilla gruesa molida de calabaza, y frijoles molidos. Y Él que es eterno [Yax Bolón Dzacab, "Gran-nuevefecundador”] lo envolvió y lo ató todo junto, y se fue al decimotercer piso del cielo. Y entonces cayeron su piel y las puntas de sus huesos aquí sobre la tierra. Y fue entonces que se escapó su corazón, porque los Trece dioses no querían que se les fuera su corazón y su semilla (Libro de Chilam Balam de Chumayel, 1998: 88).

De esta forma Bolon Dzacab habría creado el prototipo de envoltorio al guardar el principio masculino de generación de la vida, el semen, la semilla que fecunda la tierra, la vida en potencia.

Como producto de los cambios políticos y de las migraciones, el papel sagrado de los gobernantes durante el período Posclásico tuvo un desarrollo particular en la figura de los ancestros y dioses fundadores o patronos de los pueblos. Núñez de la Vega revela la identidad de los restos humanos y de los envoltorios sagrados que eran venerados en las cuevas durante el período de contacto al hablar de "los que poblaron"; los fundadores "cuyos huesos, siendo de gentiles, hasta hoy en día han venerado como si hubiesen sido santos, llevándoles sahumerio de copal y flores a las cuevas donde los tienen puestos" (Núñez de la Vega, 1988: 757). Menciona en particular a Votán, un ancestro poblador de la región chiapaneca, a quien "en alguna provincia le tienen por el corazón de los pueblos" (Núñez de la Vega, 1988: 275).

Por lo demás, el papel de las cuevas como santuarios de importancia política que resguardaban dioses y bultos sagrados, susceptibles de pillajes, pervivió en el Posclásico:

En muchas partes acostumbraban tener sus ídolos en lugares ásperos, cuevas oscuras y ocultas, metidos, por algunas razones: lo uno, por tenelles más reverencia [porque les parecía que si estuviesen donde munchas veces los viesen sería ocasión de algún menosprecio] lo otro, porque algunos de los vecinos no los hurtasen teniéndolos donde todos supiesen dellos [porque en los templos no acostumbraban tener puertas...] y lo tercero, porque los de otros pueblos o de los que tenían por enemigos, no viniesen con gente de armas a hurtallos también, y era costumbre dellos cerca de los templos no entrar, ni aposentarse gente de guerra (Las Casas, 1967: II, 216).

Si capturar a los enemigos permitía apoderarse de su fuerza o aniquilarla (Houston, Stuart y Taube, 2006: 221), apropiarse de las reliquias probablemente ofrecía las mismas alternativas. La cita precedente deja entrever que en algunos casos los envoltorios sagrados fueron hurtados para ser conservados, quedando su potencia a disposición de quien se adueñaba de ellos. Por otra parte, destruir a los dioses o las reliquias veneradas por un grupo implicaba terminar con los protectores de su territorio y socavar los vínculos ancestrales en que tenía 
fundamento el poder local de un linaje (Blomster, 2011), elemento clave en las ceremonias de transmisión del poder (Ayala, 2002: 118-119, 141-146).

Además, las reliquias parecen haber fungido como puntos propicios para la llegada o manifestación de los espíritus ancestrales, como figura en el Dintel 25 de Yaxchilán (Fitzsimmons, 2009: 137-139), por lo que su hurto o destrucción conllevaría para sus descendientes la pérdida de comunicación con ellos. Entre estas dos alternativas, las reliquias debieron de ser objeto de negociaciones y haber participado en la afirmación de alianzas (Weiss-Krejci, 2011). La literatura maya colonial proporciona algunos casos en que se explicita la importancia de los restos humanos, especialmente de las calaveras, en trances de guerra. Cuando surgieron disensiones entre los quichés se dice que "se tiraban calaveras de muertos y se atalayaban" (Popol Wuj, 1979: 100 a). En venganza por la muerte de su padre, el rey Quicab atacó Cojá, hizo prisioneros y destruyó sus cráneos (Título K’oyoi, 2009: 35). Rescatar del territorio enemigo los huesos de los propios era, por las mismas razones, primordial. Ejemplo de ello es el discurso del mismo Quicab, quien, siendo un muchacho, reunió a sus guerreros y les dijo:

Yo soy el rey. Vayamos a conquistar la ciudad de Cojá. Los huesos de mi padre están allí en Cojá. Entrad y recoged su calavera. Cuando recojáis la calavera no revolváis los huesos. Así será cuando vaya a recoger los huesos de mi padre (Guerras comunes de quichés y cakchiqueles, 2009: 158).

En el Rabinal Achi, el príncipe cautivo menciona el rostro cincelado sobre el cráneo de un ancestro suyo, que estaba en posesión de sus captores:

— ¿Es esa la copa en que bebes? [...] iPero si ese es el cráneo de mi abuelo; esa es la cabeza de mi padre, la que veo, la que contemplo! ¿No se podría hacer lo mismo con los huesos de mi cabeza, con los huesos de mi cráneo, cincelar mi boca, cincelar mi cara? (De la Garza, León Portilla y Recinos, 1992: 329).

La suerte de los cautivos más distinguidos era el sacrificio, mientras que el resto de ellos parecen haberse convertido en esclavos de su captor (Landa, 1983: 52). En ambos casos quedaban irrevocablemente sujetos a él, ya fuera en vida o a través de sus reliquias, que acompañarían al victorioso en su tumba. En las inscripciones eran llamados b'aak, "el hueso de sus captores" (Houston, Stuart y Taube, 2006: 221; Fitzsimmons, 2009: 167). Es significativo en este sentido que los términos bacçah y chuculté aludieran por igual al esclavo o esclava, preso o cautivo habidos en la guerra, así como al "despojo de los enemigos" (Bolles, 2001). Algunos tratamientos póstumos del cuerpo de los prisioneros parecen haber tenido por objetivo conformar reliquias, y otros, por el contrario, eliminarlas. Landa nos dice que "para su guerra, hacían grandes ofrendas de los despojos" (Landa, 1983: 52). Poseer el cuerpo de un cautivo implicaba la posibilidad de incidir en la fecundidad del propio grupo (Olivier, 2008) o del grupo antagonista a fin de asegurarse 
nuevos cautivos, por la manipulación adecuada de su fuerza generadora, ${ }^{20}$ o por la eliminación de su potencial dañino y de su capacidad de acción, en ocasiones mediante la antropofagia (Houston, Stuart y Taube, 2006: 221), el depósito en sitios especiales o la ejecución de tratamientos rituales determinados, como el recubrimiento y sellado con capas de material blanco (Wagner, 2006).

Otro aspecto que merece mención aquí es la exhibición y ostentación de los restos humanos. El interés que llegó a revestir apoderarse de las cabezas de los enemigos tiene su mayor manifestación plástica en el tzompantli posclásico, del que la muestra más célebre es la plataforma calcárea esculpida de Chichén Itzá a principios de dicho período. En tiempos de la conquista, en Alta Verapaz:

Ponían las cabezas de los sacrificados en unos palos sobre un cierto altar para esto solamente dedicado, donde las tenían por algún tiempo, el cual pasado, las enterraban. Decían que por ciertas razones : una, primera y principal, porque el ídolo o el dios que representaba se acordase del sacrificio que se le había hecho por servirle (...) otra, porque los que lo viesen considerasen que aquellos por el bien común fueron sacrificados ; otra, porque el rey o señor que sucediese lo viese, y antes a aquella religión añadiese que quitase; la otra, porque los enemigos que lo oyesen tuviesen temor de los ofender, porque sino fuesen ciertos que así habían de ser sacrificados (Las Casas, 1967, II: 221).

En este testimonio es manifiesto el doble objetivo político y religioso de la exposición de las cabezas y nos permite aprehender la existencia de diferentes niveles de apropiación de los restos de guerra. A nivel colectivo, la suma de contribuciones individuales a la victoria era dispuesta en un monumento público más o menos efímero que ostentaba el poderío guerrero del grupo y el prestigio de su dirigente con el fin de infundir temor y respeto, ${ }^{21}$ y de hacer patente su participación en alimentar a los dioses (Baudez, 2000: 201). Por otra parte, algunos restos trofeo eran conservados de forma individual por el guerrero de cuya proeza constituían para siempre la prueba. Así, por ejemplo, "después de la victoria, quitaban a los muertos la quijada y limpia de carne, poníansela en el brazo" (Landa, 1983: 52). En el Título de Totonicapan se habla de despojar a los guerreros de sus armas y de sus insignias "junto con el dedo pequeño de la mano y del pie" (Título de Totonicapan, 1983: 178).

\footnotetext{
${ }^{20}$ Sobre los cautivos de guerra y la intención de hacerlos proliferar, Coto consigna que "Si era de los que habían cogido en guerra (...) guardaban el miembro genital y testículos del tal sacrificado, y se los daban a una vieja que tenían por profeta para que los comiese. Y le pedían rogase a su ídolo o Qabuvil les diese más cautivos. Y entonces ellos hacían un gran convite, comiéndose al que habían sacrificado" (Coto, 1983: 520).

${ }^{21}$ Otro ejemplo de prácticas con parecidos objetivos es la tumba masiva de Zacpetén (Duncan y Schwarz, 2013).
} 
El poder de las reliquias

Tú, corazón del cielo; tú, corazón de la tierra; envoltorio de gloria,

Tú, Tohil, Avilix y Hacavitz; vientre del, cielo; vientre de la tierra

y cuatro esquinas, sólo haya paz en tu presencia

(Ximénez, 1857: 131-132).

Habiendo visto algunos nexos importantes entre las reliquias y el poder, es momento de variar la perspectiva para aprehender otros a partir de las consideraciones sobre el poder intrínseco adjudicado a estos objetos. Ambos enfoques son indisociables; se sustentan y se contienen mutuamente.

Al igual que el caudillo del pueblo mexica Huitziton, de quien hablamos al principio, Balam Quitzé, el fundador mítico del linaje Cavec, y sus compañeros eran ya muy viejos, cuando dejó a sus hijos la señal de su existencia diciendo:

Esto os dejo para que os acordéis de nosotros, esto dejo con vosotros y esta será vuestra grandeza. Ya me despedí y os avisé y estoy triste: esto dijo cuando les dejó la señal de su ser y costumbre que se llama: la majestad y grandeza envuelta, y no se sabe que es, sino que quedó envuelto y no se desató (Ximénez, 1857: 115).

El nombre quiché de este envoltorio, pisom q'aq'al, ha sido traducido como bulto de fuego, flama envuelta, don precioso, envoltorio de majestad, gloria y majestad envuelta, grandeza encerrada. ${ }^{22}$

Resulta enriquecedor contemplar estos significados a la luz de los textos que hablan de un fuego relacionado con ciertos personajes mayas. En la literatura de las tierras altas, por ejemplo, a la muerte de Gucumatz, "el Señor le dijo a un corcovado: 'Anda a aparecerte a la Señora y le dirás: El Señor ha muerto [...] y en seguida salió fuego del Señor'” (Guerras comunes de quichés y cakchiqueles, 2009: 157). De los hijos de Q'aq'awitz se dice que su poder era tal que donde pasaban la noche había "pulsares y atracciones (...), un fuego que se producía en espiral y (...) temblores de tierra" (Memorial de Sololá, 1999: 170).

La alusión al fuego, q'aq', también se usa en quiché como adjetivo para describir metafóricamente a las personas en términos de imponente grandeza. En este sentido, q'aq' suele ir asociado con tepe, préstamo del náhuatl que significa por igual autoridad, gloria y majestad, formando el compuesto q'aq'tepe (Christenson, 2016: 123). Por ejemplo, cuando Q'aq'awitz volvió con el fuego del interior del

22 Véase Ayala (2002: 54, 64). Allen Christenson, en su edición del Popol Vuh (2007: 45, 46), hace notar que el uso de las convenciones de escritura para las consonantes palatales y uvulares no siempre es empleada de forma consistente en el Popol Vuh (Christenson, 2007: 46-49), lo que puede dar pie a distintas interpretaciones, sin embargo, en la traducción original al castellano, fray Francisco Ximénez da a pisom q'aq'qal el sentido de "envoltorio de gloria” y “majestad y grandeza envuelta” (Ximénez, 1857: 115, 116, 131). 
volcán, se dice que "su rostro se había vuelto terrible" y que dijeron de él: "en verdad su poder mágico, su ciencia, su gloria y majestad (ruq'aq’al, rutepewal) son terribles; le creíamos muerto" (Memorial de Sololá, 1999: 107,164).

López Austin $(1973: 122,134,149)$ considera que se trata de un "fuego divino" que se alojaba en los cuerpos de los hombres-dioses. Propongo identificar este fuego característico de los poderosos con el calor anímico que algunos grupos mayas contemporáneos consideran que se acumula en el cuerpo humano mediante el ejercicio de cargos de importancia social, y que ha sido documentado por la etnografía bajo distintos nombres. El encontrarnos ante una fuerza anímica, capaz de mantenerse e incrementarse en el cuerpo mediante determinadas prácticas y abstinencias, parece claro en la siguiente cita sobre los fundadores quichés: "ellos tienen poder y gloria ( $q$ 'aq' e tepe) sólo porque nunca ven mujeres" (Título de Totonicapán, 1983: 89 (quiché), 180). Fray Tomás de Coto asocia la fuerza de la vejez con el sol al decir que los cakchiqueles reprendían al que se metía a hablar con los mayores donde no le habían llamado, diciéndole: "no cojas los átomos del sol, o rayos" (Coto, 1983: 201). Los efectos nocivos de tomar sol en exceso son, pues, equiparados con la exposición a la fuerza espiritual de los ancianos. La idea de una fuerza que aumenta con la edad nos remite al k'inam y a otras nociones semejantes, como el panvil de los tzotziles de San Pedro Chenalhó (Guiteras,1965). En muchas lenguas mayas se le designa con nombres que derivan de las raíces para designar "fuego" y "sol" o "día", y para aludir al fuego del sol.

Las inscripciones y las fuentes etnohistóricas dan testimonio de la antiguiedad de la concepción de esta fuerza o cualidad y de su asociación con los dirigentes al proporcionar numerosos nombres de dioses, topónimos y nombres o títulos de señores que incluyen $k^{\prime} a k^{\prime}$, portan el apelativo Kihnich ${ }^{23}$ o se refieren a un fuego o una fuerza anímica relacionados con el sol, desde el período Clásico (Velásquez, 2009: 542-551).

Erik Boot ha hecho notar que en los textos del Clásico la forma K'ihnich designaba lugares y personas, ${ }^{24}$ mientras que en el Posclásico parece haber dejado de emplearse para designar personas como lo hiciera en el Clásico, siendo reservado únicamente para dioses y lugares (como en K'inich Kakmó, K'inich Ahau). Acaso esto refleja el proceso de deificación de algunos personajes durante dicho período. Sin embargo, tal cualidad solar siguió siendo asociada con los grandes señores, como se hace patente a través del léxico que los describe.

Søren Wichmann (2004) ha propuesto para k'inich, comúnmente traducido como una referencia al sol, una lectura adicional de "caliente" y "enojado, co-

\footnotetext{
${ }^{23}$ K'inich está presente en frases nominales de gobernantes como K’inich Tahal Chak, del Clásico Temprano en Naranjo, K’inich Yax K'uk' Mo', nombre del fundador de una dinastía de Copán, después de su ascenso, y K'inich Hanab' Pakal, de Palenque. Derivados de "sol” o “calor" para dioses en los textos clásicos son K'in Ahaw, frase titular para un dios, y K’inil Kayom (Boot, 2002: 51-53).

${ }^{24}$ Sin embargo, el dios GIII de Palenque lleva este apelativo (Bassie-Sweet, 2008: 117).
} 
lérico, furioso". ${ }^{25}$ Tales significados permiten relacionarlo directamente con el k'inam, como lo señaló en un principio Alfonso Villa Rojas (1985: 189, 190).

El k'inam, derivado de k'in, "sol", es "la fuerza generadora de la vida" que está presente en todos los seres. Tiene una cualidad ambivalente ya que puede ser creadora y destructora y sus efectos pueden ser positivos o negativos, sobre distintas cosas y seres (Álvarez, 1997, III: 36, 37, 77). Se trata de un "calor" que, si bien deriva del sol o participa de él, no puede ser medido como temperatura; es más bien algo semejante al temperamento. Evon Vogt lo define como una cualidad general de la existencia que ofrece un lenguaje para describir las diferencias de poder en el universo. El estado simbólico de "calor" se emplea especialmente para referirse al poder político de un jefe, al poder ritual de un curandero o del titular de un cargo, a la fuerza sobrenatural de un hombre anciano o al poder de curación de una planta ritual (Vogt, 1979: 294, 295). Todos los entes y elementos del mundo poseen cierta medida de esta fuerza. En el ser humano, se estima que los hombres tienen más que las mujeres y que va aumentando con la edad, ${ }^{26}$ de forma que quienes han ejercido cargos han "calentado su alma" (Guiteras, 1965: 68-71, 248-249; Vogt, 1979: 46, 295), y poseen en mayor cantidad ese poder sagrado (Vogt, 1979: 59) o temperamento propio de los jefes (Villa Rojas, 1985: 188-190). El gobernante del Clásico era considerado un ser caliente; su piel se representaba de color rojo en las esculturas, reflejando así su extraordinario calor y poder, equiparables a los del sol (O'Neil, 2012: 21), y poseía un aliento, discurso o efluvio característico de los gobernantes: k'ak'al ik' (Houston, Stuart y Taube, 2006: 228). Quizá estas ideas tienen relación con la consideración del sol como un elemento masculino y con la asignación al fuego de un alma masculina, de carácter protector (Laughlin, 1975: 186), lo que haría del k'inam "la fuerza masculina generadora de vida" como propuso Cristina Álvarez (1997, III: 77).

El asiento principal de esta fuerza en el ser humano probablemente era la cabeza y, en particular, determinadas áreas de ella como la coronilla y el cabello. (Chávez, 2005: 124; Martínez, 2006: 128-130; López Austin, 1980, I: 241-243). Estas concepciones debieron de estar implicadas en las prácticas rituales en las que el cráneo, pero también otros restos como cabellos, fémures o quijadas, tenían especial importancia para los antiguos mayas. Es probable que el criterio para seleccionar determinadas partes del cuerpo sobre otras haya sido en algunos casos el de privilegiar las que estuvieran señaladamente dotadas de aquella fuerza vital a fin de lograr de ella efectos benéficos. ${ }^{27}$ Un ejemplo de tal selección

${ }^{25}$ Wichmann (2004: 77-82) y Lacadena (2003: 106) consideran que "el logograma K'IN puede no sólo transcribir la palabra k'in, "sol", sino también $k^{\prime} i[h] n$, con las acepciones relacionadas de "calor, caliente" y "enojo, cólera, enfado", bien documentadas en ch'orti'. Al poseer el sufijo -ich, el mismo valor de "tener la cualidad de", k'ihnich podría significar también "caliente, enojado, colérico, furioso".

${ }^{26}$ Estas propiedades caracterizan dicho calor y hacen posible su identificación en distintos grupos mayanses, a pesar de las distintas denominaciones que recibe (Cf. Álvarez, 1997, III: 77). Entre los tzotziles de San Pedro Chenalhó recibe el nombre de panvil (Guiteras, 1965).

${ }^{27}$ Confróntese con el tonalli (Chávez, 2005: 122; Martínez, 2006: 138). 
es que, además de las ya mencionadas estatuas de barro, la población de Yucatán en tiempos de la conquista:

hacía a sus padres estatuas de madera a las cuales dejaban hueco el colodrillo, y quemaban alguna parte de su cuerpo y echaban allí las cenizas y tapábanlo; y después desollaban al difunto el cuero del colodrillo y pegábanselo allí, enterrando los residuos como tenían de costumbre; guardaban estas estatuas con mucha reverencia entre sus ídolos (Landa, 1983: 59, 60).

Es significativo que los mayas del siglo xvı sólo se dejaban el cabello largo en algunas áreas de la cabeza, en especial "un copete en el colodrillo", ${ }^{28}$ como se lee en la Relación de Oxcutzcab, quizá con la función protectora de evitar que escapara el k'inam. ${ }^{29}$ Así, es plausible que al sellar con el cuero de esta parte la estatua-relicario dentro de la cual se conservaban las cenizas o fragmentos del cuerpo del muerto, se buscara resguardar dentro de ella la preciosa fuerza anímica, confiriendo a la imagen entera el poder esencial de aquella persona.

En el Calepino de Motul (Ciudad Real, 1995) se da al término k'inam los significados de "cosa venerable y respetable" y "fuerza, reciura, rigor y fortaleza"; puede referirse a la fuerza del fuego, del sol, de la calentura, del vino, a la "virtud como de piedras o yerbas" y al "veneno de animales". ${ }^{30}$ Es también la consecuencia de dicha virtud: "dolor de la ponzoña o de la llaga y dolor fuerte o doler así" ponzoñosos. Y es, sobre todo, "la braveza y ferocidad que traen consigo los animales bravos y fieros, y los hombres así valientes, que ponen espanto" (Ciudad Real, 1995, I: 425). ${ }^{31}$ En itzá, al k'inam alude al "peso del muerto", que puede tener consecuencias dañinas para la salud de las personas (Hoffling y Tesucún, 2000: 134), idea que remite a las emanaciones poderosas de los bultos mortuorios, como se representa en la Estela 40 de Piedras Negras (Houston, Stuart y Taube, 2006: 156).

Wichmann (2004: 80) ha destacado que el término tzotzil k'ak'al significa "caliente, sano, brillante", al igual que "día" y "sol", y puede ser considerado el equi-

${ }^{28}$ Muñoz, 1983: 355. Véase también la Relación de Muxuppipp (Santillana y Chi, 1983: 378).

${ }^{29}$ Para los nahuas, por ejemplo, "es peligroso el corte de cabellos en la parte posterior de la cabeza porque se propicia con ello la salida del tonalli" (López Austin, 1980, I: 225). Sobre los mayas, véase Barrera (1938: 91).

${ }^{30}$ Es muy posible que el nivel de fuerza k'inam que poseen determine los objetos incluidos en los envoltorios medicinales. Aguirre Beltrán dice al respecto: "En la parafernalia del oficio nunca falta la bolsa de cuero o tafetán en que se conservan las más diversas medicinas profilácticas: yerbas alucinógenas de reconocida potencia (...) pedrezuelas de color y forma insólitos; extraños insectos, cabellos, garras, huesos humanos, fragmentos de cordón umbilical, cabos de vela y otras materias que tienen la virtud de ser el vehículo o continente de fuerzas anímicas que les convierten en remedios mágicamente protectores" (Aguirre Beltrán, 1973: 198).

31 Ah kinam es "cosa ponzoñosa; bravo, que causa de suyo espanto y temor, o aquel a quien los otros le tienen respeto" (Ciudad Real, 1995, I: 46) Otros términos próximos son: Kinaan: "cosa que manda, reina y prevalece", Kinil: "estar próspero, reinar y mandar", y el verbo Kinamcunah ba: "hacerse respetable uno y hacer que le teman" (Ciudad Real, 1995, I: 426). 
valente funcional de k'ihnich. K'ak'al, k'inam y k'ihnich son, por lo tanto, términos que aluden por igual a las cualidades de bravura, grandeza y majestad propias de quien ejerce el poder. El léxico asociado es revelador de una concepción del poder político-religioso en la en que el temor era indisociable del respeto.

Por último, hace falta cruzar el puente establecido por Villa Rojas y por Wichmann hacia las lenguas quicheanas para llegar a las reliquias y al envoltorio de majestad, el pisom q'aq'al. Fray Domingo de Basseta (2005: 214, 353) consigna en quiché los significados de majestad, grandeza y vanagloria para cacal, tepeual, ${ }^{32}$ que también designaban a una "grave persona". Cacalah uinac era "hombre bravo" (Basseta, 2005: 86). Cacal refiere asimismo a la ira y al rencor. En cakchiquel el mismo término se empleaba para "furia o furor, crueldad, enojo" (Coto, 1983: 119, 243). Mientras que nim u cakal, u tepeual se traducen como "poder, majestad". Dentro del mismo campo semántico se encuentran en yucateco los términos: kaak, "la cólera con que uno muestra su indignación e ira" (Ciudad Real, 1995, I: 403), mientras que kaakil como adjetivo hace referencia a los principales y los más fuertes, por ejemplo, u kaakil katun se refería a "los principales capitanes y más fuertes soldados del ejército” (Ciudad Real, 1995, I: 404). Kakal es "tener miedo”, y ásKakalna, “casa pública, mesón, casa real” (Pérez, 1877: 164), siendo éste el nombre que recibe en el Chilam Balam de Chumayel la iglesia mayor del centro de Mérida. ${ }^{33}$ Recordemos que en el Popol Vuh, Hacavitz fue colocado en una montaña despejada, acaso una pirámide, que tomó su nombre y que recibe el apelativo de nima q'aq' ja. ${ }^{34}$ El equivalente cakchiquel a estos términos parece ser cak hay, ${ }^{35}$ que aparece en el Vocabulario de fray Tomás de Coto en distintas entradas de gran interés. Dicha expresión muestra las asociaciones conceptuales comprendidas en la problemática de las reliquias que acabamos de discutir ya que designa, de manera por demás significativa, los diferentes sitios en que se resguardaban las reliquias y las potestades sagradas contenidas en los envoltorios: la montaña, la cueva y la pirámide. De acuerdo con fray Tomas de Coto, cak hay hace referencia a "otero" (Coto, 1983: 385), a "montecillos redondos, o montones de tierra y piedra que hacían los antiguos a mano, y hay muchos

${ }^{32}$ En todos los casos se mantiene la ortografía maya original de los diccionarios, mientras que he modernizado las transcripciones del castellano.

${ }^{33}$ En el texto del Chilam Balam de Chumayel: "Chumuc cah Ti hoo Yglesia mayor, U kakal na, U uitzil na, Akab na", The Book of Chilam Balam of Chumayel (Roys, 1933: 43, 126). Existe cierto vínculo entre la cueva y la iglesia, acaso por ser ambas sitios sagrados y de entierro o depósito de restos humanos y de reunión pública para fines rituales que en un momento llegaron a coexistir, como lo consigna Margil de Jesús en 1704, en la ceremonia dedicada a los ancestros que se realizaba con el envoltorio sagrado de cada chinamital, primero en la montaña y después en la iglesia, a donde se habían trasladado las tumbas (Cavaleri y Ruz, 1988).

34 "Gran casa de fuego". El término de nim ja, "gran casa", hace referencia al linaje. Véase la discusión sobre casa y linaje en Gillespie (2000b).

${ }^{35}$ La transcripción de la ortografía plantea incertidumbres para la traducción. Ello deja pie a la lectura como q'aq'jay, casa de fuego, o como kaqjay, casa roja. Véanse las traducciones del término en quiché en las ediciones del Popol Vuh de Tedlock (1996: 302), que opta por la segunda, y de Christenson que se inclina por la primera (Popol Vuh, 2007: 198). 
en algunas partes" (Coto, 1983: 355), y por último a "cuevas antiguas donde guardaban ídolos" (Coto, 1983: 120). ${ }^{36}$

Igualmente, Coto consigna el empleo de este término como metáfora para dirigirse al señor principal, revelando de forma inequívoca su identificación con los ancestros, con el árbol central de la ceiba y con la montaña-pirámide o la cueva donde reposaban sus predecesores, asignándole el mismo sitio que a aquellos, en su papel de progenitor, protector del pueblo y dispensador de todos los bienes. Así, cuando solicitaban favores de sus principales, se dirigían a ellos como sigue:

At ahau, at nu te, at nu tata, quere at inub, cak hay, pa ka vi; ko paran ch'a xe, quere at ka parabal, at ka muhibal: Ah señor, tú eres nuestro padre y madre, eres como el árbol de la ceiba, como el otero o cerrillo, eres nuestro amparo y sombra (Coto, 1983: 385). ${ }^{37}$

Dejemos a fray Bernardo de Lizana clausurar estas reflexiones exhibiendo el vínculo de continuidad que unía a la población con los personajes destacados a través de sus reliquias, al hablar del carácter taumatúrgico y oracular de Itzam Nah Thul, que continuó sin ruptura a través de Kabul, su mano obradora:

Quando vivía este rey ídolo, le consultaban los pueblos las cosas que sucedían en las partes remotas, y les decía esto y otras cosas futuras. Así mismo, le llevaban los muertos, y dicen que los resucitaba y a los enfermos sanaba. Murió este rey y levantaron altares y un oráculo [...] donde pusieron la figura de la Mano, que les servía de memoria. Y dizen que allí le llevaban los muertos y enfermos y que, allí, resucitaban y sanaban en tocándolos la Mano (Lizana, 1995: 62).

Hemos atisbado algunas de las características de las reliquias mayas en distintos contextos acercándonos a su carácter adivinatorio, protector, de sanación. Fueron prendas de sujeción de o a un poder y, en el caso de los poderosos, mediadoras entre los dioses y los hombres, pues habían sido en vida las personas de cuyos cuerpos eran materia, testimonio tangible de la continuidad del papel protector asignado a los grandes hombres y de su fuerza generadora de vida.

En este trabajo me he ocupado únicamente de los restos humanos; sin embargo, un testimonio sobre el último resuello proporciona indicios que obligan a cuestionar la importancia del soporte material corporal:

Cuando quiera, pues, que algún señor moría, tenía aparejada una piedra preciosa que le ponían en la boca cuando quería expirar, en la cual creían que le tomaban

\footnotetext{
${ }^{36}$ Hago notar que, de forma ordinaria, la cueva se denominaba pec, según se indica en la misma entrada, por lo que puede entenderse que resguardar lo sagrado es lo que otorga ese apelativo a la cueva, o bien que sólo determinadas cuevas "antiguas" poseían el carácter sagrado que les permitiría acoger a los ídolos.

${ }^{37}$ El énfasis es mío. Véase también su uso "para encarecer que uno es rico y poderoso y que es de respeto" (Coto, 1983: 492).
} 
el ánima, y en expirando, con ella muy livianamente le refregaban el rostro. [...] la piedra era estimada por cosa divina, y así lo nombraban hombre de Dios, como si dijeran que aquel hombre se había trasladado a los dioses hecho ya divino, y por esta errada consideración ofrecían a estas piedras, en ciertos tiempos sacrificios. (Las Casas, 1967, II: 526).

Aunque Las Casas no da aquí el término nativo, por su traducción como "hombre de Dios" parece probable que se tratara de vinak qu, el mismo que era dado a las figuras hechas con cenizas, de las que antes hablé; de manera que cabe plantear que tanto las estatuillas como la piedra pudieron fungir como soportes de una fuerza anímica y demostrar de igual manera la presencia del espíritu del ancestro. Esta transferencia ritual de las propiedades vitales parece ser la misma que opera, por ejemplo, en la animación de edificios mediante la inserción de un sacrificio gracias a la propiedad de las fuerzas anímicas de circular entre cosas de distinta naturaleza.

Podemos, por lo pronto, concluir que los envoltorios con reliquias, objetos de materia ambivalente que transitaron el ciclo completo de la existencia, conciliando en sí las tensiones entre las fuerzas del mundo y del inframundo, fungieron entre los mayas como el soporte enigmático de la identidad y la fuerza del grupo de cuyo mundo social se convertían en el centro. A través de ellos, el corazón de los muertos se mantenía vivo en el seno de las familias y de la comunidad como “corazón de las casas” y "corazón de los pueblos”, constituyendo una reserva del poder seminal de la muerte que continuaría fructificando en el porvenir, por vía de la memoria, ya que, como señaló López Medel, "honrando a los muertos provocaban a los vivos para otras tales y mayores obras" (López Medel, 1990: 245).

Por otra parte, la importancia de las reliquias en la sociedad maya corrobora la concepción mesoamericana de que solamente quien ha ofrendado su vida por los otros, sólo quien la ha repartido entre la comunidad, como un sacrificado o como el titular de un cargo público -casos de los que el gobernante es el exponente por excelencia-, ${ }^{38}$ es capaz de resurgir del mundo subterráneo, de manera semejante a como lo hace el sol, para continuar prodigando los dones vivíficos de su fiera, imponente e inextinguible majestad.

\section{Bibliografía}

Aguirre Beltrán, Gonzalo

1973 Medicina y Magia. El proceso de aculturación en la estructura colonial. México: Instituto Nacional Indigenista (Colección de Antropología Social).

\footnotetext{
38 Sobre el sacrificio simbólico del gobernante en Mesoamérica, ver Dehouve, 2016; Olivier, 2015; Taube, 1988.
} 
Álvarez, Cristina

1997 Diccionario etnolingüístico del idioma maya-yucateco colonial, tomo III. México: Universidad Nacional Autónoma de México, Dirección General de Publicaciones, 3 volúmenes.

Astor-Aguilera, Miguel Ángel

2010 The Maya World of Communicating Objects. Quadripartite Crosses, Trees and Stones. New Mexico: University of New Mexico Press.

Ayala Falcon, Maricela

2002 El bulto ritual de Mundo Perdido, Tikal. México: Universidad Nacional Autónoma de México, Instituto de Investigaciones Filológicas, Centro de Estudios Mayas (Cuadernos del Centro de Estudios Mayas, 27).

Avendaño y Loyola, fray Andrés de

1997 Relación de las dos entradas que hice a la conversión de los gentiles ytzáex y cehaches, Temis Vayhinger-Scheer (ed.). Möckmühl: Flemming (Fuentes Mesoamericanas, 1).

Basseta, fray Domingo de

2005 [1698] Vocabulario de la lengua quiché, René Acuña (ed.). México: Universidad Nacional Autónoma de México, Instituto de Investigaciones Filológicas, Centro de Estudios Mayas (Fuentes para el Estudio de la Cultura Maya, 12).

Baudez, Claude-François

2000 "El botín humano de las guerras mayas: decapitados y cabezas-trofeo", $L a$ guerra entre los antiguos mayas: Memoria de la Primera Mesa Redonda de Palenque, pp. 189-204, Silvia Trejo (ed.). México: Consejo Nacional para la Cultura y las Artes, Instituto Nacional de Antropología e Historia.

2002 Une histoire de la religion des Mayas. Du panthéisme au panthéon. Paris: Bibliothèque Albin Michel.

Barrera Vázquez, Alfredo (ed.)

1938 Fray Diego de Landa. Relación de las Cosas de Yucatán. Mérida: Edición Yucateca.

1980 Diccionario Maya Cordemex: Maya-Español, Español-Maya. Mérida, Yucatán: Ediciones Cordemex.

Benavente "Motolinía”, fray Toribio de

1969 [1541] Historia de los Indios de Nueva España, Edmundo O’Gorman (ed.). México: Porrúa.

Blom, Frans

1954 "Ossuaries, Cremation and Secondary Burials among the Maya of Chiapas, Mexico“, Journal de la Société des Américanistes, 43: 123-136. DOI: 10.3406/jsa.1954.2418. 
Blomster, Jeffrey P.

2011 "Bodies, Bones and Burials: Corporeal Constructs and Enduring Relationships in Oaxaca", Living with the Dead. Mortuary Ritual in Mesoamerica, pp. 102-160, James L. Fitzsimmons e Izumi Shimada (eds.). Tucson: The University of Arizona Press.

Bolles, David

2001 Combined Dictionary-Concordance of the Yucatecan Mayan Language, disponible en <http://www.famsi.org/reports/96072/index.html> [consultado el 20 de septiembre de 2013].

Boot, Erik

2002 A Preliminary Classic Maya-English/English-Classic Maya Vocabulary of Hieroglyphic Readings. Leiden: Leiden University.

Bourdin, Gabriel L.

2007 El cuerpo humano entre los mayas. Una aproximación etnolingüística. Mérida: Universidad Autónoma de Yucatán.

Brown, Linda

2005 "Planting the Bones: Hunting Ceremonialism at Contemporary and Nineteenth-Century Shrines in the Guatemalan Highlands", Latin American Antiquity, 16 (2): 131-146.

2009 "Communal and Personal Hunting Shrines around Lake Atitlan, Guatemala", Maya Archaeology, I: 36-59.

Casas, fray Bartolomé de las

1967 [1536] Apologética historia sumaria cuanto a las cualidades, dispusición, descripción, cielo y suelo destas tierras, y condiciones naturales, policias, repúblicas, manera de vivir e costumbres de las gentes destas Indias Occidentales y Méridionales, cuyo imperio soberano pertenece a los Reyes de Castilla, Edmundo O'Gorman (ed.). México: Universidad Nacional Autónoma de México, Instituto de Investigaciones Históricas, 2 volúmenes.

Castillo, Cristóbal del

2001 [1600] Historia de la venida de los mexicanos y de otros pueblos e historia de la conquista. Federico Navarrete Linares (trad.). México: Consejo Nacional para la Cultura y las Artes (Cien de México).

Cavaleri, Danièle y Mario Humberto Ruz

1988 "La deidad fingida. Antonio Margil y la religiosidad quiche del 1704", Estudios de Cultura Maya, 17: 213-267. DOI: 10.19130/iifl.ecm.1988.17.600.

Chase, Diane Z. y Arlen F. Chase

2011 "Ghosts amid the Ruins. Analyzing Relationships between the Living and the Dead among the Ancient Maya at Caracol, Belize", Living with the Dead. 
Mortuary Ritual in Mesoamerica, pp. 78-101, James L. Fitzsimmons e Izumi Shimada (eds.). Tucson: The University of Arizona Press.

Chávez Guzmán, Mónica

2005 "El sol como fundamento curativo de las terapias mayas yucatecas en el período colonial”, Estudios de Cultura Maya, XXVIII: 121-139. DOI: http://dx.doi. org/10.19130/iifl.ecm.2006.28.615.

Christenson, Allen J.

2001 Art and Society in a Highland Maya Community. The Altarpiece of Santiago Atitlán. Austin: University of Texas Press.

2016 The Burden of the Ancients. Maya Ceremonies of World Renewal from the PreColumbian Period to the Present. Austin: University of Texas Press.

Ciudad Real, fray Antonio de

1995 [ca. 1568] Calepino de Motul. Diccionario maya-español, Ramón Arzápalo Marín (ed.). México, Universidad Nacional Autónoma de México, Dirección General de Asuntos del Personal Académico, Instituto de Investigaciones Antropológicas, 3 volúmenes.

Coto, fray Thomás de

1983 [ca. 1656] Thesaurus Verborum: Vocabulario de la lengua cakchiquel y guatemalteca, René Acuña (ed.). México: Universidad Nacional Autónoma de México, Instituto de Investigaciones Filológicas, Centro de Estudios Mayas.

Dehouve, Danièle

2016 La realeza sagrada en México (siglos XVI-XXI). México: Secretaría de Cultura, Instituto Nacional de Antropología e Historia (Colección Investigaciones).

Duncan, William N. y Kevin R. Schwarz

2013 "Partible, Permeable, and Relational Bodies in a Maya Mass Grave", Commingled and Disarticulated Human Remains: Working Toward Improved Theory, Method, and Data, pp. 149-170. Anna J. Osterholtz, Kathryn M. Baustian y Debra L. Martin (eds.). New York: Springer-Verlag New York Inc.

Durán, fray Diego

1967 [1581] Historia de las Indias de Nueva España e islas de Tierra Firme, Ángel Ma. Garibay K. (ed.). México: Porrúa, 2 volúmenes.

Eberl, Markus

2005 Muerte, entierro y ascensión. Ritos funerarios entre los antiguos mayas. Mérida: Ediciones de la Universidad Autónoma de Yucatán.

El libro de los libros del Chilam Balam

1972 Alfredo Barrera Vázquez y Silvia Rendón (trads.). México: Fondo de Cultura Económica (Colección Popular 42). 
Fitzsimmons, James L.

2009 Death and the Classic Maya Kings. Austin: University of Texas Press.

Fitzsimmons, James L. e Izumi Shimada (eds.)

2011 Living with the Dead. Mortuary Ritual in Mesoamerica. Tucson: University of Arizona Press

Garza, Mercedes de la, Miguel León Portilla y Adrián Recinos (eds.),

$1992 \quad$ Literatura maya. Caracas: Fundación Biblioteca Ayacucho.

Geller, Pamela L.

2011 "Getting a Head Start in Life. Pre-Columbian Maya Cranial Modification from Infancy to Ancestorhood", The Bioarchaeology of the Human Head: Decapitation, Decoration, and Deformation, pp. 241-261, Michelle Bonogofsky (ed.). Gainesville: University Press of Florida.

Gillespie, Susan

2000a "Maya 'Nested Houses': The Ritual Construction of Place”, Beyond Kinship: Social and Material Reproduction in House Societies, pp. 135-160, R. Joyce y S. Gillespie (eds.). Philadelphia: University of Pennsylvania Press.

2000b "Rethinking Ancient Maya Social Organization: Replacing "Lineage" with "House", American Anthropologist, 102 (3): 467-484. DOI: 10.1525/ aa.2000.102.3.467.

2001 "Personhood, Agency, and Mortuary Ritual: A Case Study from the Ancient Maya”, Journal of Anthropological Archaeology, 20: 73-112. DOI:10.1006/ jaar.2000.0369.

2002 "Body and Soul among the Maya: Keeping the Spirits in Place", Archeological Papers of the American Anthropological Association, 11 (1): 67-78. DOI: 10.1525/ ap3a.2002.11.1.67.

Guernsey, Julia y F. Kent Reilly (eds.)

2006 Sacred Bundles. Ritual Acts of Wrapping and Binding in Mesoamerica, Barnardsville, North Carolina: Boundary and Archaeological Research Center.

"Guerras comunes de quichés y cakchiqueles"

2009 Francis Polo Sifontes (introd.), Crónicas Mesoaméricanas II, pp. 151-161, Ho-

[1554] racio Cabezas Carcache (ed.). Guatemala: Universidad Mesoamericana.

Guiteras Holmes, Calixta

1965 Los peligros del alma. Visión del mundo de un tzotzil. México: Fondo de Cultura Económica.

Helmke, Christophe y James E. Brady

2014 "Epigraphic and Archaeological Evidence for Cave Desecration in Ancient Maya Warfare", A Celebration of the Life and Work of Pierre Robert Colas, pp. 195-227, Christophe Helmke y Frauke Sachse (eds.). Munich: Anton Saurwein. 
Hertz, Robert

1970 "Contribution à une étude sur la représentation collective de la mort", Socio-

[1907] logie réligieuse et folklore, pp. 14-79. Paris: Les Presses Universitaires de France.

Hofling, Charles A. y Tesucún, Félix F.

2000 Tojt'an maya itzaj: diccionario maya itzaj-castellano. Guatemala: Cholsamaj.

Houston, Stephen D., David Stuart y Karl Taube

2006 The Memory of Bones. Body, Being and Experience among the Classic Maya. Austin: University of Texas Press.

Houston, Stephen D. y Tom Cummins

2004 "Body, Presence, and Space in the Andean and Mesoamerican Rulership", Palaces of the Ancient New World, pp. 359-398, Susan Toby Evans y Joanne Pillsbury (eds.). Washington: Dumbarton Oaks Trustees for Harvard University.

Lacadena García-Gallo, Alfonso

2003 "El corpus Glífico de Ek’ Balam, Yucatán, México”, FAMSI Reports < http:// www.famsi.org/reports/0157es/index.htlm> [consultado el 14 de noviembre de 2015].

Landa, fray Diego de

1983 [1566] Relación de las cosas de Yucatán. México: Editorial Porrúa.

Laughlin, Robert M.

1975 The Great Tzotzil Dictionary of San Lorenzo Zinacantán. Washington D.C.: Smithsonian Institution Press (Smithsonian Contributions to Anthropology, 19).

Le Guen, Olivier

2008 "Ubèel pixan: el camino de las almas. Ancestros familiares y colectivos entre los mayas yucatecos”, Península, III (1): 84-120.

Libro de Chilam Balam de Chumayel

1998 Mercedes de la Garza (ed.). México: Consejo Nacional para la Cultura y las Artes, Dirección General de Publicaciones.

Lizana, fray Bernardo de

1995 [1633] Devocionario de Nuestra Señora de Izamal y conquista espiritual de Yucatán, René Acuña (ed.). México: Universidad Nacional Autónoma de México, Instituto de Investigaciones Filológicas, Centro de Estudios Mayas (Fuentes para el estudio de la cultura maya, 12).

López Austin, Alfredo

1973 Hombre-dios. Religión y política en el mundo náhuatl. México: Universidad Nacional Autónoma de México, Instituto de Investigaciones Históricas.

1980 Cuerpo humano e ideología: las concepciones de los antiguos nahuas. México: Universidad Nacional Autónoma de México, Instituto de Investigaciones Antropológicas, 2 volúmenes. 
López Medel, Tomás

1990 [ca. 1565] De los tres elementos: Tratado sobre la naturaleza y el hombre del Nuevo Mundo, Berta Ares Queija (ed.). Madrid: Alianza Editorial.

Lorenzen, Karl James

2005 "Ancestor Deification in Ancient Maya Ritual and Religion. Late Postclassic Community Shrines and Family Oratories", Journal of Washington Academy of Sciences, vol. 91 (4): 25-47.

Martínez González, Roberto

2006 "El tonalli y el calor vital: algunas precisiones", Anales de Antropología, 40 (II): 117-151.

Masson, Marilyn A. y Carlos Peraza Lope

2004 "Commoners in Postclassic Maya Society: Social Versus Economic Class Constructs", Ancient Maya Commoners, pp. 197-224, Jon C. Lohse y Fred Valdez, Jr. (eds.). Austin: University of Texas Press.

Matos Moctezuma, Eduardo

2010 "La muerte del hombre por el hombre: el sacrificio humano", El sacrificio humano en la tradición religiosa mesoamericana, pp. 43-64, Leonardo López Luján y Guilhem Olivier (coords.). México: Instituto Nacional de Antropología e Historia, Universidad Nacional Autónoma de México, Instituto de Investigaciones Históricas.

Maza García de Alba, María del Rocío

2014 "Les dieux, les ancêtres, les sacrifiés: les reliques dans la tradition religieuse maya”, tesis de maestría en Ciencias Históricas, Filológicas y Religiosas. Paris: École Pratique des Hautes Études.

McAnany, Patricia

1998 "Ancestors and the Classic Maya Built Environment", Function and Meaning in Classic Maya Architecture, pp. 271-298, S. Houston (ed.). Washington D.C.: Dumbarton Oaks.

Mendelson, Michael E.

1958 "A Guatemalan Sacred Bundle”, Man, 58: 121-126. DOI: https://doi. org/10.2307/2796271.

Miller, Mary Ellen y Karl A. Taube

1993 The Gods and Symbols of Ancient Mexico and the Maya: An Illustrated Dictionary of Mesoamerican Religion. London: Thames and Hudson.

Muñoz Zapata, Hernando

1983 [1581] "Relación de Oxcutzcab", Relaciones Historico-geográficas de la gobernación de Yucatán, vol. I, pp. 353-357, Mercedes de la Garza (coord.), México: Universidad Nacional Autónoma de México, Instituto de Investigaciones Fi- 
lológicas, Centro de Estudios Mayas (Fuentes para el estudio de la cultura maya, 1), 2 volúmenes.

Núñez de la Vega, fray Francisco

1988 [1702] Constituciones Diocesanas del Obispado de Chiapa, María del Carmen León Cázares y Mario Humberto Ruz (eds.). México: Universidad Nacional Autónoma de México, Instituto de Investigaciones Filológicas, Centro de Estudios Mayas (Fuentes para el estudio de la cultura maya, 6).

Olivier, Guilhem

2008 "Le cerf et le roi: modèle sacrificiel et rite d'intronisation dans l'ancien Mexique”, Journal de la Société des Américanistes, 94 (1): 191-203.

2015 Cacería, sacrificio y poder en Mesoamérica: tras las huellas de Mixcóatl "Serpiente de Nube", México: Centro de Estudios Mexicanos y Centroamericanos, Universidad Nacional Autónoma de México, Instituto de Investigaciones Históricas, Fondo de Cultura Económica.

O’Neil, Megan E.

2012 Engaging Ancient Maya Sculpture at Piedras Negras, Guatemala. Norman: University of Oklahoma Press.

Pérez, Juan Pío

1877 Diccionario de la lengua Maya. Mérida de Yucatán: Imprenta Literaria de Juan F. Molina Solís.

Popol Vuh. Sacred Book of the Quiché Maya People

2007 Traducción y notas de Allen J. Christenson. Mesoweb publications, versión electrónica de la publicación original de 2003, <www.mesoweb.com/publications/Christenson/PopolVuh.pdf> [consultado el 20 de agosto de 2016].

Popol Wuj (libro de acontecimientos)

1979 [ca. 1700] Traducción directa del manuscrito del padre Jiménez, traducción de Adrián I. Chávez. México: Instituto Nacional de Antropología e Historia, Ediciones de la Casa Chata.

Roys, Ralph

1933 The Book of Chilam Balam de Chumayel. Washington, D.C.: Carnegie Institution of Washington (Publication 438).

Ruz Sosa, Mario Humberto

1985 "Copanaguastla, "Mère du Coton": un village maya-tzeltal à l'époque coloniale", tesis de doctorado en Etnología. Paris: École des Hautes Études en Sciences Sociales.

Santillana, Pedro de y Gaspar Antonio Chi

1983 [1581] "Relación de Muxuppipp", Relaciones historico-geográficas de la gobernación de Yucatán, vol. I, pp. 375-382, Mercedes de la Garza (ed.). México: 
Universidad Nacional Autónoma de México, Instituto de Investigaciones Filológicas, Centro de Estudios Mayas (Fuentes para el Estudio de la Cultura Maya, 1), 2 volúmenes.

Serafín, Stanley y Carlos Peraza Lope

2007 "Human Sacrificial Rites Among the Maya of Mayapán: A Bioarchaeological Perspective", New Perspectives on Human Sacrifice and Ritual Body Treatments in Ancient Maya Society, pp. 232-250. Vera Tiesler y Andrea Cucina (eds.). New York: Springer.

Serna, Jacinto de la

2014 [1656] Tratado de las idolatrías, supersticiones, hechicerías, y otras costumbres de las razas aborígenes de México. Barcelona: Linkgua.

Sharer, Robert J.

1999 La civilización maya. México: Fondo de Cultura Económica.

Smith, Augustus Ledyard

1962 "Residential and Associated Structures at Mayapan”, Mayapan, Yucatán, México, pp. 165-320, Harry E. D. Pollock, Ralph Roys, Tatiana Proskouriakoff y A. Ledyard Smith (eds.). Washington D.C.: Carnegie Institution of Washington (Occasional Publication, 619).

Sotelo Santos, Laura Elena

2002 "Los dioses, energías en el espacio y en el tiempo”, Religión Maya, pp. 83114, Martha Ilia Nájera y Mercedes de la Garza (coords.). Madrid: Trotta (Enciclopedia Iberoamericana de religiones).

Spotts, John Michael

2013 "Local Achievers or Immigrant Elites? Ancestral Relics or Warrior Trophies? Some Classic Period Cultural Historical Questions Addressed Through Strontium Isotope Analysis of Burials from Western Belize", tesis para obtener el grado de Master of Arts in Anthropology. San Diego: San Diego State University.

Stone, Andrea J.

1995 Images from the Underworld: Naj Tunich and the Tradition of Maya Cave Painting. Austin: University of Texas Press.

Taube, Karl A.

1988 "A Study of Classic Maya Scaffold Sacrifice”, Maya Iconography, pp. 331-351, Elisabeth P. Benson y Gillett G. Griffin (eds.). Princeton: Princeton University Press.

1998 "The Jade Hearth: Centrality, Rulership, and the Classic Maya Temple", Function and Meaning in Classic Maya Architecture, pp. 427-478, Stephen D. Houston (ed.). Washington D.C.: Dumbarton Oaks. 
Tedlock, Barbara

1992 Time and the Highland Maya. Albuquerque: University of New Mexico Press.

Tedlock, Dennis

1996 Popol Vuh: The Definitive Edition of the Mayan Book of the Dawn of Life and the Glories of Gods and Kings. Nueva York y Londres: Touchstone.

Tiesler, Vera

2007 "Las tradiciones funerarias en el norte de Campeche. Un ensayo etnoarqueológico", Tafonomía, medio ambiente y cultura. Aportaciones a la antropología de la muerte, pp. 161-181. México: Universidad Nacional Autónoma de México, Instituto de Investigaciones Antropológicas.

2012 Trasformarse en maya. El modelado cefálico entre los mayas prehispánicos y coloniales. México: Universidad Nacional Autónoma de México, Universidad Autónoma de Yucatán.

Tiesler, Vera y Andrea Cucina (eds.)

2007 New Perspectives on Human Sacrifice and Ritual Body Treatments in Ancient Maya Society. New York: Springer.

Título de Totonicapán

1983 [1554] Robert M. Carmack y James L. Mondloch (edición facsimilar, transcripción y traducción). México: Universidad Nacional Autónoma de México, Instituto de Investigaciones Filológicas, Centro de Estudios Mayas (Fuentes para el estudio de la cultura maya, 3).

Título K'oyoi

2009 [ca. 1560] Robert M. Carmack y James L. Mondloch (eds. y trads.), Crónicas Mesoaméricanas II, pp. 15-67, Horacio Cabezas Carcache (ed.). Guatemala: Universidad Mesoamericana.

Tozzer, Alfred

1941 Landa's Relación de las Cosas de Yucatan: A Translation. Cambridge, Massachusetts: Harvard University (Papers of the Peabody Museum of American Archaeology and Ethnology, 18).

Tuan, Yi-Fu

1974 Topophilia: A Study of Environmental Perception, Attitudes, and Values. Englewoods Cliffs: Prentice-Hall.

Van Gennep, Arnold

1981 Les rites de passage. Paris: Picard.

Vargas Pacheco, Ernesto y Patricia Santillán S.

1992 "Sistema de enterramientos en Tulum", Estudios de Cultura Maya, XIX: 67-

112. DOI: http://dx.doi.org/10.19130/iifl.ecm.1992.19.468. 
Vega Villalobos, María Elena

2017 El gobernante maya: historia documental de cuatro señores del periodo Clásico. México: Universidad Nacional Autónoma de México, Instituto de Investigaciones Históricas, Fideicomiso Felipe Teixidor y Monserrat Alfau de Teixidor.

Velásquez García, Erik

2009 "Los vasos de la entidad política de 'Ik': una aproximación histórico-artística. Estudio sobre las entidades anímicas y el lenguaje gestual y corporal en el arte maya clásico", tesis de doctorado en Historia del Arte, México: Universidad Nacional Autónoma de México, Facultad de Filosofía y Letras.

Villa Rojas, Alfonso

1982 "Breves consideraciones sobre la creencia del 'mal de ojo”, Anales de Antropología, 19 (II): 147-161.

1985 “La imagen del cuerpo humano según los mayas de Yucatán”, Estudios etnológicos: los mayas, pp. 187-198, A. Villa Rojas (ed.). México: Universidad Nacional Autónoma de México, Instituto de Investigaciones Antropológicas.

Villagutierre Sotomayor, Juan de

1985 [1735] Historia de la Conquista de la Provincia de El Itzá [edición facsimilar]. México: Centro de Estudios de Historia de México, Condumex.

Vogt, Evon Z.

1979 Ofrendas para los dioses. Análisis simbólico de rituales zinacantecos. México: Fondo de Cultura Económica (Sección de Obras de Antropología).

Wagner, Elisabeth

2006 "White Earth Bundles - The Symbolic Sealing and Burial of Buildings among the Ancient Maya", Acta Mesoamericana 16: Jaws of the Underworld. Life, Death, and Rebirth Among the Ancient Maya, pp. 55-69, Pierre R. Colas, Genevieve Le Fort y Bodil Liljefors Persson (eds.). Markt Schwaben: Verlag Anton Saurwein.

Weiss-Krejci, Estella

2011 "The Role of Dead Bodies in Ancient Maya Politics: Cross-Cultural Reflections on the Meaning of Tikal Altar 5", Living with the Dead: Mortuary Ritual in Mesoamerica, pp. 17-52, James Fitzsimmons e Izumi Shimada (eds.). Tucson: University of Arizona Press.

Wichmann, Søren

2004 "The Names of Some Major Classic Maya gods", Continuity and Change-Mayan Religious Practices in Temporal Perspective. 5th European Maya Conference, University of Bonn, December 2000, Acta Americana, 14: 77-86, Daniel Graña Behrens, Nikolai Grube, Christian M. Prager, Frauke Sachse, Stefanie Teufel y Elisabeth Wagner (eds.). Markt Schwaben: Verlag Anton Saurwein. 
Ximénez, fray Francisco

1857 [ca. 1700] Las historias del origen de los Indios de esta provincia de Guatemala, traducidas de la lengua quiché al castellano para más comodidad de los ministros del s. Evangelio ... Exactamente según el texto español del manuscrito original que se halla en la Biblioteca de la Universidad de Guatemala, Karl Ritter von Scherzer (transcripción, introducción y notas). Viena: Carl Gerold \& Sohn.

Zamora Acosta, Elías

1985 Los mayas de las tierras altas en el siglo xVI. Tradición y cambio en Guatemala. Sevilla: Publicaciones de la Excelentísima Diputación Provincial de Sevilla (Sección Historia, V Centenario del descubrimiento de América, 5). 